\section{Luminescence dating applied to Saint-Irénée's church (Lyon, France)}

\section{Armel Bouvier, ${ }^{1,2}$ \\ Jean-François Reynaud, ${ }^{3}$ Pierre Guibert, ${ }^{1}$ Christian Sapin ${ }^{4}$ \\ Institut de Recherche sur les Archéomatériaux, Centre de Recherche en Physique Appliquée à l'Archéologie, IRAMAT-CRP2A UMR 5060, Université de Bordeaux 3, Maison de l'Archéologie, Pessac; ${ }^{2}$ Centre d'Innovation et de Recherche pour l'Analyse et le Marquage (CIRAM), Pessac; ${ }^{3}$ Laboratoire \\ Archéométrie et Archéologie-UMR 5138, Université Lumière Lyon 2; ${ }^{4}$ Laboratoire Archéologie, Culture et Société-UMR 8894, Université de Bourgogne, Dijon, France}

\begin{abstract}
The aim of the study presented here is to propose a new view on the chronology of early medieval buildings in Europe and on the related building modes. If several studies have proved the efficiency of this multidisciplinary process, the case of St. Irenee's church is very representative of the contributions of such an approach. This church is one of the oldest witnesses of the Christianization in Lyon, capital city of Gauls, and of its evolution under the aegis of Burgonds. However the small number of preserved remains of its early states has shown uncertainties in the interpretation of the chronology of the building use. There are two possibilities: is it the monument described by Gregory of Tours at the end of the $6^{\text {th }}$ century? Or is it the result of the Burgond building politics at around the $9^{\text {th }}$ century? Luminescence dating on architectural ceramics brought then a new approach very complementary of the historic and archaeological data, yielding new interrogations on the use and reuse of ancient material. Some evidence allowed lifting the veil on the sanctuary origins and its evolution through time. Finally, different building phases have been determined and allowed to understand the transformation of the church between its foundation and the $10^{\text {th }}$ century.
\end{abstract}

\section{Introduction}

St. Irénée's church is one of the key-sites preserved from the Late Antiquity in France. It is located in the town of Lyon, whose history is particularly rich, since it is one of the earliest Christianised cities of Gaul. This is due to its administrative importance as a capital of the provinces of Gaul until the late $3^{\text {rd }}$ century. Even after the slump of the Roman Empire, Lyon's status remains important, as it was the capital of the Burgond kingdom. Indeed since the $2^{\text {nd }}$ century, a first Christian community settled in Lyon which quickly became a famous religious and intellectual centre.

St. Irénée's church is supposed to house the graves of the saint and two of his companions. This yield to an important cult place, even more since the location of the church is on the hill of Fourvière on a Gallo-Roman necropolis. The hill being one of the centers of the ancient city, where was a part of the monumental finery of the town, which is significant for our study. According to our point of view, investigating in Lyon is very interesting, since it is one of the rare cities where the early Christian bishop quarter was preserved. The church knew at least seven phases of total or partial rebuilding before displaying its current state. Amongst these different building phases, only the early ones are concerned by our study (Figure 1).

Despite the archaeological study was particularly well carried out (Reynaud and Puel, 2006), it could not however shed light on some uncertainties about the phasing of the building. In addition, the few written sources are ambivalent. Gregory of Tours, historian of the $6^{\text {th }}$ century in Gaul, mentioned a crypt housing the relics of St. Irénée in Lyon where he lived in 560 AD. Two other texts provide further indications, one is anonymous and the second was a sermon written by Avit, one of the earliest bishops of Lyon. The latter mentioned a low church as large as the upper church in the Burgond capital. For this period, the only possibilities are Lyon or Geneva. Comparisons with local or regional buildings allow to propose a dating of the $5^{\text {th }}$. early $6^{\text {th }}$ century for the walls. As well, we can propose the $5^{\text {th }}-6^{\text {th }}$ century for the Merovingian decorative opus, but the latter could be reused (Reynaud, 1998). Rows of bricks are not typochronological markers, since they had been used for a long period. It was therefore difficult to date the crypt. Indeed some features (rows of bricks, alternation of voussoirs) could belong to Gregory of Tours' times but, its typology (crypt-hall with an aisled nave) was closer to the Carolingian or Ottonian period.

In regards of these questions, a sampling campaign was undertaken in October 2007 in the view of luminescence dating.

\section{Materials and Methods}

Fourteen samples were taken out by drilling under water cooling: three from the brick vous-
Correspondence: Armel Bouvier, Maison de l'Archéologie, Esplanade des Antilles, Domaine Universitaire, 33607 Pessac, France.

Tel. +33.0557.124553 - Fax: +33.0557 .124550$

E-mail: armel.bouvier@ciram-art.com

Key words: Late Antiquity, architecture, luminescence dating.

Acknowledgments: we would like to thank for their financial support the CNRS (French National Center for Scientific Research) and particularly the European Research Group on architectural ceramic building materials, the French Ministery of Research and Upper Education for granting a doctoral scholarships and the Conseil Régional d'Aquitaine for funding the experimental work displayed in this paper. In addition, we would like to thank Dr F.X. Le Bourdonnec and N. Rampnoux for their technical support.

Citation: Bouvier A, Reynaud J-F, Guibert P, Sapin C, 2014. Luminescence dating applied to SaintIrénée's church (Lyon, France). In: RH Tykot (ed.), Proceedings of the $38^{\text {th }}$ International Symposium on Archaeometry - May $10^{\text {th }}-14^{\text {th }}$ 2010, Tampa, Florida. Open Journal of Archaeometry 2:5259.

Presented at the $38^{\text {th }}$ International Symposium on Archaeometry - May $10^{\text {th }}-14^{\text {th }} 2010$, Tampa, Florida.

This work is licensed under a Creative Commons Attribution 3.0 License (by-nc 3.0).

(C) Copyright A. Bouvier et al., 2014

Licensee PAGEPress, Italy

Open Journal of Archaeometry 2014; 2:5259

doi:10.4081/arc.2014.5259

soirs above the northern lintel, remain of the early ways into the crypt; three others were sampled in the brick voussoirs above a roundheaded window at the south east of the apse; the eight others were sampled in the facing of the north western wall of the way into the crypt, on three different rows of bricks.

In the laboratory, after drying, every sample was prepared following the same process: a part of it was used for high resolution gamma spectrometry, another one was analyzed using microscopic and analytical methods to characterize the raw material, and the last part was prepared for luminescence experiments.

High resolution gamma spectrometry was used to determine the radioactivity characteristics of the brick, data which are required for the age calculation. For this purpose, a fraction of the sample was powdered by crushing, homogenized, and then conditioned into a plastic tube of $5.5 \mathrm{~cm}^{3}$ that was sealed in order to avoid a radon loss, a gas belonging to the uranium series, for daughter of ${ }^{238} \mathrm{U}$. To restore the equilibrium state between radon $\left({ }^{222} \mathrm{Rn}\right)$ 
and its parent radium $\left({ }^{226} \mathrm{Ra}\right)$, perhaps perturbed by the preparation, the sample was stored for 4 weeks before the measurement (Guibert et al., 2009).

Thin sections of each sample were observed in natural and polarized light with a petrographic microscope. These observations might provide provenience signatures in some cases, and the detection of the potential presence of highly radioactive minerals, which could create local heterogeneities in irradiation. Furthermore, the chemical composition of each sample was determined by scanning electron microscopy energy dispersive X-ray spectroscopy (SEM-EDS) analyses, in order to check the chemical homogeneity of the bricks that could indicate a common provenience (or not) of the clay material. These data are also used to determine the self-absorption ratio of gamma rays emerging from the sample during gamma spectrometry measurements (Guibert et al., 2009).

Quartz grains the size of which ranged between 80 and $200 \mu \mathrm{m}$ were used to determine the equivalent dose by thermoluminescence (and complementary optically stimulat- ed luminescence measurements for one sample). The preparation technique has already been detailed in Blain et al. (2007) and Bouvier et al. (2010): the aim is to select quartz grains by dissolving the fired clay matrix, notably by the use of $\mathrm{H}_{2} \mathrm{SiF}_{6}$ as an etchant.

Thermoluminescence (TL) dating was performed using the multiple aliquots with added doses and signal regeneration protocol (Guibert et al., 1996). Experimental parameters were the following ones: heating from room temperature to $500^{\circ} \mathrm{C}$ at a heating rate of $4^{\circ} \mathrm{C} / \mathrm{s}$ in wet nitrogen atmosphere $\left(96 \% \mathrm{~N}_{2}, 4 \%\right.$ $\mathrm{H}_{2} \mathrm{O}$ vapour), with a heat plateau at $190^{\circ} \mathrm{C}$ for two minutes. Detection spectral range was between 350 and $475 \mathrm{~nm}$ obtained by two optical filters Schott BG12 (Advanced Optics SCHOTT AG, Mainz, Germany) and one IR rejector filter, in conjunction with a EMI 9813 QA photomultiplier tube. Irradiations were delivered by a ${ }^{90} \mathrm{Sr}^{-}{ }^{90} \mathrm{Y} \beta$ source with a dose rate around $0.064 \mathrm{~Gy} / \mathrm{s}( \pm 1.5 \%)$ in January 2010 .

Several steps are necessary to the equivalent dose determination. The first one consists in TL measurements of the natural signal with added $\beta$ doses on a first series of aliquots. The second step consists in TL measurements of regenerated signal after $\beta$ irradiations, on a series of other annealed aliquots. The $\beta$ doses given are chosen to surround those given at the first step. A luminescence growth curve is deduced from experimental data from the second measurements series and shift to the previous experimental points (Guibert et al., 1996) according to a least square slide method.

The annealing conditions of the archaeological material between the two steps of the equivalent dose determination are determined to avoid sensitization of TL induced by the thermal treatment. By this operation we finally supposed that the same electronic state of quartz as after the brickmaking is obtained. In practice, the natural TL signal recorded with the archaeological material is compared to the regenerated one by irradiating the annealed aliquots after heating them for one hour at different temperatures in air ranging from 400 to $800^{\circ} \mathrm{C}$. The chosen temperature is the one that creates the same shape of the regenerated thermoluminescence curves as the natural or natural and dose added ones (Roque et al., 2004).

Table 1. Presentation of the data obtained for each masonry structure.

\begin{tabular}{|c|c|c|c|c|c|c|}
\hline Sample code & Location & K $(\%)$ & $\mathrm{U}(238 \mathrm{U})(\mathrm{ppm})$ & $\mathrm{U}(226 \mathrm{Ra})(\mathrm{ppm})$ & $\mathrm{U}(210 \mathrm{~Pb})(\mathrm{ppm})$ & Th (ppm) \\
\hline 11998 & Accesses to the crypt & $2.55 \pm 0.04$ & $3.45 \pm 0.23$ & $3.12 \pm 0.05$ & $3.09 \pm 0.32$ & $13.95 \pm 0.17$ \\
\hline 11999 & & $1.90 \pm 0.02$ & $3.21 \pm 0.14$ & $2.99 \pm 0.03$ & $3.14 \pm 0.21$ & $13.61 \pm 0.12$ \\
\hline 12000 & & $2.44 \pm 0.04$ & $4.40 \pm 0.24$ & $4.15 \pm 0.05$ & $4.65 \pm 0.36$ & $15.43 \pm 0.18$ \\
\hline 12002 & & $2.60 \pm 0.04$ & $2.72 \pm 0.21$ & $2.63 \pm 0.04$ & $2.59 \pm 0.30$ & $12.87 \pm 0.16$ \\
\hline 12003 & & $2.70 \pm 0.04$ & $6.75 \pm 0.26$ & $5.25 \pm 0.05$ & $5.37 \pm 0.34$ & $14.21 \pm 0.16$ \\
\hline 12004 & & $2.88 \pm 0.03$ & $5.68 \pm 0.21$ & $5.75 \pm 0.05$ & $6.02 \pm 0.34$ & $15.62 \pm 0.15$ \\
\hline 12005 & & $2.53 \pm 0.03$ & $8.66 \pm 0.24$ & $5.90 \pm 0.05$ & $5.95 \pm 0.32$ & $16.30 \pm 0.14$ \\
\hline 12006 & South-eastern window & $1.79 \pm 0.02$ & $2.92 \pm 0.14$ & $3.01 \pm 0.03$ & $2.61 \pm 0.20$ & $12.50 \pm 0.12$ \\
\hline 12007 & & $2.18 \pm 0.03$ & $3.35 \pm 0.16$ & $3.42 \pm 0.03$ & $3.03 \pm 0.22$ & $13.32 \pm 0.13$ \\
\hline 12008 & & $2.82 \pm 0.04$ & $7.30 \pm 0.24$ & $7.12 \pm 0.06$ & $6.85 \pm 0.36$ & $19.84 \pm 0.17$ \\
\hline 12009 & Northern lintel & $2.40 \pm 0.03$ & $5.44 \pm 0.19$ & $4.08 \pm 0.04$ & $4.24 \pm 0.26$ & $13.14 \pm 0.13$ \\
\hline 12010 & & $2.75 \pm 0.04$ & $9.92 \pm 0.33$ & $6.60 \pm 0.06$ & $6.79 \pm 0.41$ & $17.11 \pm 0.19$ \\
\hline 12011 & & $2.26 \pm 0.03$ & $6.42 \pm 0.20$ & $5.24 \pm 0.04$ & $5.47 \pm 0.29$ & $13.94 \pm 0.13$ \\
\hline
\end{tabular}

Table 2. Presentation of equivalent dose values determined by thermoluminescence and optically stimulated luminescence measurements, annealing temperature used before regeneration in thermoluminescence, and environmental and global annual doses.

\begin{tabular}{|c|c|c|c|c|c|c|c|}
\hline $\begin{array}{l}\text { Sample } \\
\text { reference }\end{array}$ & Location & $\begin{array}{l}\text { Paleodose } \\
\text { (Gy) with total } \\
\text { uncertainty }\end{array}$ & $\begin{array}{l}\text { Annealing } \\
\text { temperature } \\
\left({ }^{\circ} \mathrm{C}\right)\end{array}$ & $\begin{array}{c}\text { Environmental } \\
\text { dose rate } \\
\text { (mGy/yr) }\end{array}$ & $\begin{array}{l}\text { Total } \\
\text { dose rate } \\
\text { (mGy/yr) }\end{array}$ & $\begin{array}{c}\text { Age (yr) and } \\
1 \sigma \\
\text { uncertainty }\end{array}$ & Date (AD) \\
\hline $\begin{array}{l}11998 \\
11999 \\
12000 \\
12002 \\
12005\end{array}$ & Access to the crypt & $\begin{array}{l}5.05 \pm 0.28 \\
4.61 \pm 0.42 \\
6.82 \pm 0.41 \\
4.07 \pm 0.24 \\
8.34 \pm 0.61\end{array}$ & $\begin{array}{l}500 \\
600 \\
800 \\
650 \\
550\end{array}$ & $\begin{array}{l}0.71 \pm 0.05 \\
1.18 \pm 0.03 \\
0.89 \pm 0.03 \\
1.14 \pm 0.03 \\
1.13 \pm 0.03\end{array}$ & $\begin{array}{l}3.45 \pm 0.10 \\
3.41 \pm 0.09 \\
3.80 \pm 0.11 \\
3.79 \pm 0.09 \\
4.45 \pm 0.12\end{array}$ & $\begin{array}{c}1463 \pm 93 \\
1353 \pm 130 \\
1796 \pm 119 \\
1075 \pm 70 \\
1875 \pm 146\end{array}$ & $\begin{array}{c}547 \pm 93 \\
657 \pm 130 \\
214 \pm 119 \\
935 \pm 70 \\
135 \pm 146\end{array}$ \\
\hline $\begin{array}{l}12006 \\
12007 \\
12008 \text { (TL) } \\
12008 \text { (OSL) }\end{array}$ & South-eastern window & $\begin{array}{l}5.58 \pm 0.33 \\
7.68 \pm 0.56 \\
6.99 \pm 0.55 \\
5.69 \pm 0.20\end{array}$ & $\begin{array}{c}600 \\
750 \\
625 \\
-\end{array}$ & $\begin{array}{l}0.78 \pm 0.03 \\
0.70 \pm 0.02 \\
0.86 \pm 0.03\end{array}$ & $\begin{array}{l}2.74 \pm 0.11 \\
3.08 \pm 0.13 \\
4.04 \pm 0.15\end{array}$ & $\begin{array}{c}2037 \pm 143 \\
2495 \pm 204 \\
1595 \pm 135 \\
1425 \pm 76\end{array}$ & $\begin{array}{c}27 \mathrm{BC} \pm 143 \\
485 \mathrm{BC} \pm 204 \\
415 \pm 135 \\
585 \pm 76\end{array}$ \\
\hline $\begin{array}{l}12009 \\
12010 \\
12011\end{array}$ & Northern lintel & $\begin{array}{l}6.21 \pm 0.47 \\
7.04 \pm 0.80 \\
5.72 \pm 0.70\end{array}$ & $\begin{array}{l}650 \\
700 \\
700\end{array}$ & $\begin{array}{l}1.00 \pm 0.03 \\
1.18 \pm 0.04 \\
0.93 \pm 0.03\end{array}$ & $\begin{array}{l}3.75 \pm 0.16 \\
4.73 \pm 0.25 \\
3.72 \pm 0.19\end{array}$ & $\begin{array}{l}1668 \pm 142 \\
1488 \pm 182 \\
1538 \pm 200\end{array}$ & $\begin{array}{l}342 \pm 142 \\
522 \pm 182 \\
472 \pm 200\end{array}$ \\
\hline
\end{tabular}

TL, thermoluminescence; OSL, optically stimulated luminescence. 
Since the $\mathrm{H}_{2} \mathrm{SiF}_{6}$ etching does not dissolve the external part of the coarse grains of quartz, it is necessary to take into account the contribution coming from the alpha irradiation of grains by the clay matrix. For these purposes a standard k-value (that accounts for the relative sensitivities between alpha and beta irradiation) of $0.08 \pm 0.02$ was fixed. It is a mean value for high temperature region of quartz TL. We estimated that a measurement of alpha efficiency was not necessary in this case because of the very weak contribution of the alpha particles to the global irradiation (external alpha irradiation of coarse grains).

The different contributions to the annual dose were determined following two different ways. Environmental $\gamma$ and cosmic rays contributions were measured by in situ dosimetry. The dosimeters used are $\mathrm{CaSO}_{4}: \mathrm{Tm}$ powders conditioned in brass tubes, that had been exposed to the environmental radioactivity for one year in the holes left by drilling at the precise sample locations.

The internal contribution to the annual dose was measured with a high-resolution spectrometer (Canberra-Eurisys Mesures EGPC 200 P17; Canberra, Knoxville, TN, USA) and the U, Th and $K$ contents are converted into and $\beta$ dose rates (Adamiec and Aitken, 1998). The water content used for age calculation was determined after water saturation of the samples. For samples coming from the accesses to the crypt (BDX 11998 to 12005), the saturation percentage was very low (between 3 and 4\%) but, in general, the samples from the outside of the church showed a much higher saturation value (between 11 and 20\%). Finally, each sample was given an average water content value corresponding to the half saturation percentage.

\section{Results and Discussion}

Concerning the study of the radiochemical content of the samples, three values of the equivalent uranium contents are determined from the gamma spectra: i) the head of $U$ series, gives a concentration denoted $\mathrm{U}\left({ }^{238} \mathrm{U}\right)$ which is derived from activities of ${ }^{235} \mathrm{U},{ }^{234} \mathrm{Th}$ and ${ }^{234 \mathrm{mPa}}$ isotopes; ii) the intermediate part of $\mathrm{U}$ series, called $\mathrm{U}\left({ }^{226} \mathrm{Ra}\right)$, is measured from the ${ }^{214} \mathrm{~Pb}$ and ${ }^{214} \mathrm{Bi}$ isotopes within the laboratory conditions of equilibrium between ${ }^{222} \mathrm{Rn}$ and ${ }^{226} \mathrm{Ra}$; and iii) the end of series, called $\mathrm{U}\left({ }^{210} \mathrm{~Pb}\right)$, is measured from the ${ }^{210} \mathrm{~Pb}$ gamma line.

As presented in Table 1, uranium content deduced from $\mathrm{U}\left({ }^{226} \mathrm{Ra}\right)$ and $\mathrm{U}\left({ }^{210} \mathrm{~Pb}\right)$ are equivalent which means no significant radon exchange occured since the insertion of bricks in masonry structures (Bouvier et al., 2010). Radiochemical composition allowed us to discriminate two groups of samples. Indeed, a group of bricks exhibits small values of the

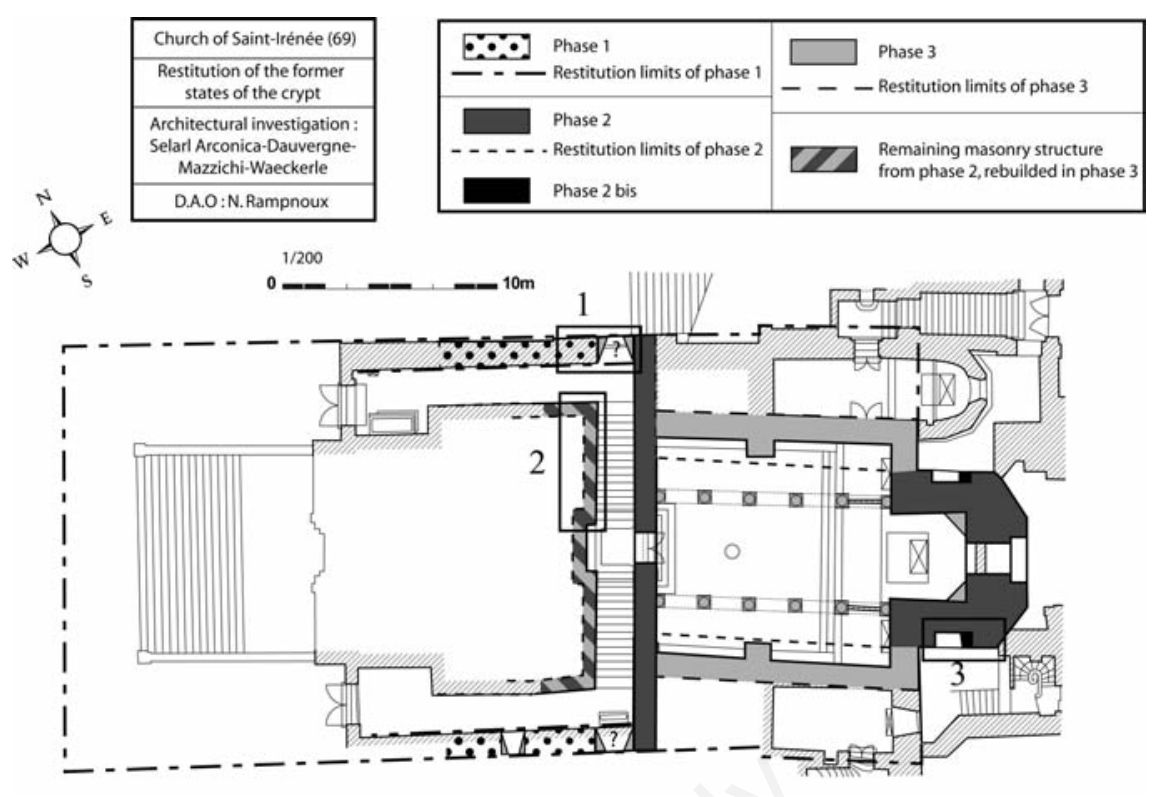

Figure 1. Actual scheme of the church of Saint-Irénée and restitution of the three first hypothetical building phases. Numbers correspond to the sampled masonry structures: 1 corresponds to the northern lintel; 2 is the accesses to the crypt; 3 is the south-eastern window. 
$\mathrm{U}\left({ }^{238} \mathrm{U}\right) / \mathrm{Th}$ and $\mathrm{U}\left({ }^{226} \mathrm{Ra}\right) / \mathrm{Th}$ ratios and an equilibrated uranium chain. The other group presents much higher ratios and for some of them a marked disequilibrium (Figure 2). This can be interpreted as enrichment in the head of the chain in uranium element of the raw material that was altered prior to the brickmaking.

Regarding the measurements obtained (Table 1), an examination of the distribution of luminescence dates is made for each masonry structure, and a global analysis of the results is then presented.

The dates obtained on the bricks of the northern lintel constitute a simple case (BDX $12009,12010,12011)$. The dates are quite homogeneously distributed between the mid $4^{\text {th }}$ century and the early $6^{\text {th }}$ century. It can be assumed that the brickmaking for each sample is contemporary. For this masonry structure a weighted mean of $407 \mathrm{AD} \pm 120$ is suggested for the construction. The mean is obtained by weighting every individual age, proportionally to the inverse of its statistical variance.

The bricks above the south-eastern window (BDX 12006, 12007 and 12008) present dates significantly spread, probably due to different periods of production. Some of them are likely reused from Gallo-Roman masonries, but it cannot however be ascertained that all bricks are reused. If we make the assessment that the more recent bricks are truly characterizing the construction of the masonry structure, the south-eastern window should have been constructed around $556 \mathrm{AD} \pm 70$. The accesses to the crypt present a more complex situation. The dates on these bricks (BDX 11998, 11999, $12000,12002$ and 12005$)$ raise again the question of reuse. For these five dates, three cases can be distinguished: one brick seems to be a probable reuse of Roman material (BDX 12000 and 12005), three others, considering their uncertainties, could have been produced during Late Antiquity (BDX 11998 and 11999) and the last one (BDX 12002), during the end of Early Middle Ages. It seems meaningful to group together the dates obtained on BDX 11998,11999 . It appears very likely that BDX 12000 is also in a Roman reuse situation. Whatever these results, several assumptions can be raised. It can be considered either that the masonry structure was built in one time, or that there is evidence for at least two periods of construction. In the former case, we might consider that $80 \%$ of the bricks are in a reuse situation and the only chronological information would be provided by BDX 12002 . In the latter case, a superposition of two building phases can be suggested, the first one being characterized by the dates obtained on BDX 11998 and 11999, and the second phase, by the date obtained on BDX 12002. This hypothesis seems more likely, because of the stratigraphical relationship between the different parts of the structure. If only BDX 11998 and 11999 are taken into account to date this building phase, a mean date around $580 \pm 80 \mathrm{AD}$ can be proposed and the following building phase is only dated by BDX 12002 around $935 \pm 70 \mathrm{AD}$.

The analysis of all the dates obtained shows three periods of brick production: Roman Antiquity, Late Roman Antiquity and the end of the Early Middle Ages. The four bricks belonging to the Antiquity were obviously reused (BDX 12000, 12005, 12006 and 12007). Five samples dated to the Late Antiquity were produced between the $5^{\text {th }}$ century and the $7^{\text {th }}$ century (BDX 11998, 11999, 12008, 12009 and 12011), which underlines a major building phase for this period. One date obtained highlights a building phase related to the end of the Early Middle Ages (BDX 12002).

\section{Conclusions}

The combination of luminescence data with archaeological ones (Table 2) allows us to elaborate a better chronology of the building phases succession. If only the youngest date obtained characterises the age of the three structures studied, $91 \%$ of the bricks dated would be in situation of being reused from earlier buildings. However, the dating results show a concentration of dates between the $5^{\text {th }}$ and the early $6^{\text {th }}$ century. If we consider that concentration is the result of a unique building phase, we can attempt at dating more accurately this event. So, the contemporaneousness between the six samples (BDX 11998, 11999, 12008, 12009, 12010 and 12011) was checked with a chi-square test. This test allows checking the normality of age distribution. If successful, it shows that the dispersion of the ages obtained is essentially due to the measurements uncertainties. The chi-square value of 3.15 for a confidence interval 2.20-10.6 at $80 \%$ of probability was very satisfying, meaning that it is consistent with the contemporaneousness assumption. For this building phase a mean date around $539 \pm 61 \mathrm{AD}$ can be suggested. This result matches with historical and archaeological data, allowing considering this building phase as the one described by Gregory of Tours near $573 \mathrm{AD}$, when he lived in Lyons. The other main facts highlighted by this study are the presence of Roman reuse in two of the three structures sampled (south-eastern window and accesses to the crypt). Finally, the accesses to the crypt seem to provide an evidence for another building phase around the $10^{\text {th }}$ century $(935 \pm 70 \mathrm{AD})$, which is consistent with the episode of reconstruction ordered by the bishop Rémi in the mid $9^{\text {th }}$ century.

If this study succeeded in clarifying the chronology of the ancient building phases of Saint-Irénée's church, it also underlined what parts of the dating procedure need improve- ments. The example of the south-eastern window perfectly illustrates the problems of representativeness this study was confronted to: among three dates, two indicate Antiquity. Shall we conclude that two-thirds of the brick elements in this masonry structure are Roman reused or is this overrepresentation of ancient bricks only an artefact due to the few bricks sampled? At least a dozen of samples could have clarified this ambiguity.

Furthermore, the assumption of contemporaneousness for all dates between the $5^{\text {th }}$ and the $6^{\text {th }}$ century could be discussed. If there were two or more building phases during this period, the insufficient resolution of thermoluminescence dating cannot discriminate them. Aiming the best accuracy between two building phases very close in time implies an increase of the number of samples characterizing these phases. Working on a statistically significant number of samples requires a better efficiency of dating protocols, by increasing the rate of operation, in order to allow a more efficient accumulation of data.

\section{References}

Adamiec G, Aitken MJ, 1998. Dose rate conversion factors, update. Ancient TL 16:37-50.

Blain S, Guibert P, Bouvier A, Vieillevigne E, Bechtel F, Sapin C, Baylé M, 2007. TL-dating applied to building archaeology: the case of the medieval church Notre-Dame-Sous-Terre (Mont-Saint-Michel, France). Radiat Meas 42:1483-91.

Bouvier A, Pinto G, Guibert P, Nicolas-Méry D, Baylé M, 2010. Luminescence dating applied to medieval architecture: the north east tower of the Avranches dungeon (Manche, France). Archéosciences 34:59-68.

Guibert P, Lahaye C, Bechtel F, 2009. The importance of U-series disequilibrium of sediments in luminescence dating: a case study at the Roc de Marsal cave (Dordogne, France). Radiat Meas 44:223-31.

Guibert P, Vartanian E, Bechtel F, Schvoerer M, 1996. Non-linear approach of TL response to dose: polynomial approximation. Ancient TL 14:7-14.

Reynaud J-F, 1998. [Lugdunum christianum; Lyon du IVe au VIII ${ }^{\mathrm{e}}$ s.: topographie, nécropoles et édifices religieux]. [Article in French]. Doc Arch Fr 69:176-82.

Reynaud J-F, Puel 0, 2006. [Etude archéologique de la crypte de Saint-Irénée]. [Book in French]. Service Régional de l'Archéologie, Lille, pp 42.

Roque C, Guibert P, Vartagnan E, Vieillevigne E, Bechtel F, 2004. Changes in luminescence properties induced by thermal treatments; a case study at Sipan and Trujillo Moche sites (Peru). Radiat Meas 38:119-26. 